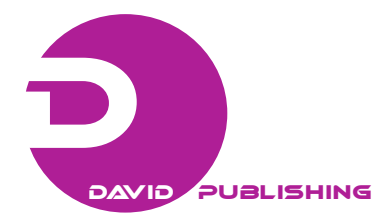

\title{
A Study of the Structural, Optical and Electrical Properties of SnS Thin Films Modified by Plasma
}

\author{
Aarón Gómez ${ }^{1}$, Horacio Martínez ${ }^{2}$, Manuela Calixto-Rodríguez ${ }^{3}$, David Avellaneda ${ }^{4}$, Pedro Guillermo Reyes ${ }^{1}$ \\ and Osvaldo Flores ${ }^{2}$ \\ 1. Laboratorio de Física Avanzada, Facultad de Ciencias, Universidad Autónoma del Estado de México, Estado de México, México \\ 2. Laboratorio de Espectroscopía, Instituto de Ciencias Físicas, Universidad Nacional Autónoma de México, Cuernavaca, Morelos, \\ México \\ 3. Intituto de Energía Renovable, Universidad Nacional Autónoma de México, Cuernavaca, Morelos, México \\ 4. Facultad de Ingeniería Mecánica y Eléctrica, Universidad Autónoma de Nuevo León, México
}

Received: February 21, 2012 / Accepted: March 26, 2013 / Published: June 25, 2013.

\begin{abstract}
SnS}$ thin films were deposited by chemical bath deposition technique and treated using glow discharge $\mathrm{O}_{2}$ plasma. The pressure discharge was 3 Torr, discharge voltage of $2.5 \mathrm{kV}$ and $20 \mathrm{~mA}$ of discharge current. The as-deposited and treated thin films were characterized by X-ray diffraction, scanning electron microscopy and energy dispersive X-ray analysis. The photoconductivity and electrical effects of $\mathrm{SnS}$ have been studied. The $\mathrm{SnS}$ thin films had an orthorhombic crystalline structure. The optical gap changed from 1.61 to $1.84 \mathrm{eV}$ due to the $\mathrm{O}_{2}$ plasma treatment. The conductivity shows a marked increase with the treatment, from $2.56 \times 10^{-6}(\Omega \cdot \mathrm{cm})^{-1}$ for as-deposited film until $0.10(\Omega \cdot \mathrm{cm})^{-1}$ for the film treated at $180 \mathrm{~min}$. This result is a suitable range of conductivity for the improvement of the solar cell with $\mathrm{SnS}$ as an absorber material.
\end{abstract}

Key words: SnS thin films, plasma treatments, chemical bath deposition, optical and electrical properties.

\section{Introduction}

During the last five years $\mathrm{SnS}$ thin films have been intensively studied [1-13]. The tin sulphide ( $\mathrm{SnS})$ films have some attractive features: (1) they show both direct and indirect band gaps $\left(E_{g}\right)$ with values reported in the range of 1-1.6 eV with direct and indirect transitions, depending on the method of preparation [1-6, 8, 12]; (2) they show p-type conductivities and large absorption coefficients $(\alpha)$ in the order of $10^{4}-10^{5} \mathrm{~cm}^{-1}[1-3,6]$, which enables the absorption of most incident sunlight; (3) there are a layered semiconductors with some inert surface-free dangling bonds; (4) it is a semiconducting material that exhibits both the $\mathrm{p}$ - and n-type conduction depending on the concentration of tin [9]. The above characteristics of $\mathrm{SnS}$, along with their abundance of

Corresponding author: Aarón Gómez, Dr., research field: plasma physics. E-mail: aaron@fis.unam.mx. about $2 \mathrm{ppm}$ of $\mathrm{Sn}$ in the earth's crust may be considered reasonable proposal for developing photovoltaic devices and photo-detectors in which thin films of this semiconductor plays an important role.

Various techniques such as two-stage process (sputtering-sulfurization) [1], chemical bath deposition (CBD) [2-5], sulfurization [6, 7], spray pyrolysis [8-10], pulse electro-deposition [11], RF sputtering [12], thermal evaporation [13, 14] and atomic layer deposition (ALD) [15] have been employed to fabricate $\mathrm{SnS}$ thin films. Also, SnS nanostructures have been grown by hydrothermal synthesis [16]. CBD technique is known as a simple, low temperature and low cost deposition technique that can be applied to large area quite easily. On the other hand, post-deposition treatment (annealing) is the most common method used to improve the 
characteristics of thin films. However, the gas plasma treatments have been probed as a suitable technology for the modification on the structural, optical and electrical characteristics of the thin films [4, 17-20].

In this paper, we examine the changes in the structural, optical and electrical characteristics of $\mathrm{SnS}$ thin films, obtained by CBD method, with post-deposition gas plasma treatments in oxygen at different times.

\section{Experiments}

\subsection{Experimental Details}

SnS thin films used in this study were deposited by CBD technique [21, 22]. The bath solution was prepared as follows: $1 \mathrm{~g}$ of $\mathrm{SnCl}_{2} \cdot 2 \mathrm{H}_{2} \mathrm{O}$, dissolved in 5 $\mathrm{mL}$ of acetone was mixed in $12 \mathrm{~mL}$ of $3.7 \mathrm{M}$ of triethanolamine solution. Then $8 \mathrm{~mL}$ of $1 \mathrm{M}$ thioacetamide solution was added and $\mathrm{pH}$ was adjusted to 6.0 by addition of $10 \mathrm{~mL}$ of $4 \mathrm{M} \mathrm{NH}_{3}$ solution, and then de-ionized water was added to the solution to make a total volume of $100 \mathrm{~mL}$. Glass substrates (microscope slides of $1.25 \mathrm{~cm} \times 4 \mathrm{~cm}$ ) were placed in glass container with the deposition solution, previously the glass substrates were degreased, rinsed thoroughly on distilled water, and dried. Deposition temperature for the films was set of $60{ }^{\circ} \mathrm{C}$, and the duration of deposition process was $6 \mathrm{~h}$. After deposition the SnS films were washed with de-ionized water and dried in the air at room temperature.

\subsection{Plasma Treatments}

The SnS thin films were treated using glow discharge $\mathrm{O}_{2}$ plasma at a pressure of 3 Torr. The experimental arrangement used to produce the pulse plasma was described on detail elsewhere $[4,9]$. The plasma system has two stainless steel circular plate electrodes. The electrodes are positioned horizontally at the center of the reaction chamber, with $5 \mathrm{~mm}$ of separation between them. Samples were placed in the bottom electrode, and the gas was injected into the reaction chamber through the front flange. The same gas connection was used for the pressure sensor (MKS 317). The base pressure $\left(\sim 7 \times 10^{-3}\right.$ Torr $)$ of the discharge chamber was maintained using a mechanical pump (Trivac D-84) and purged with the working gas at 3 Torr for several times in order to remove the background gases. The discharge voltage (Bertan Series $105,1 \mathrm{~kW}$ ) was $2.5 \mathrm{kV}$, and the discharge current was $20 \mathrm{~mA}(50 \mathrm{~W})$. The time treatment was performed at 20, 40, 60 and $180 \mathrm{~min}$.

\subsection{Morphology and Thickness Characterization of Films}

The surface morphology of the SnS thin films was studied by scanning electron microscopy (SEM) using a LEO 1450 VP system.

The thickness $(t)$ of films was determined by using the Swanepoel method [23].

\subsection{Structural Characterization of Films}

The structural properties of the $\mathrm{SnS}$ films were studied by X-ray diffraction (XRD) with a Rigaku D MAX-2000 powder diffractometer that used $\mathrm{Cu} \mathrm{K \alpha}$ $(\lambda=0.154056 \mathrm{~nm})$ radiation with $2 \theta$ in the range $10^{\circ}-70^{\circ}$. The average crystalline grain size was calculated using Scherrer's formula based on the XRD patterns [24]:

$$
D=\frac{K \lambda}{\beta \cos (\theta)}
$$

where, $D$ is the average crystalline (grain) size, $K$ is a constant $(\sim 1), \lambda$ is the $\mathrm{X}$-ray wavelength, $\beta$ is the full-width at half-maximum (FWHM) of XRD peaks and $\theta$ is the Bragg angle [23].

\subsection{Optical Characterization of Films}

The optical direct transmittance $(T)$ and total (near normal specular) reflectance $(R)$ spectra were measured in the wavelength range 250-2,500 nm using a Varian (Cary 5000) spectrophotometer. The measurements were calibrated using air and mirror-aluminized as reference surfaces.

From the $R$ and $T$ spectra the optical absorption coefficients $(\alpha)$ were obtained [21]. 
The direct optical band gap $\left(E_{g}\right)$ for $\mathrm{SnS}$ films was obtained by optical absorption measurements and by plotting $(\alpha h v)^{2}$ versus photon energy $(h v)$ and using the following relation [25]:

$$
(\alpha h v)^{2}=A\left(h v-E_{g}\right)
$$

\subsection{Electrical Characterization of Films}

The electrical conductivity of the $\mathrm{SnS}$ thin films was determined at room temperature using a programmable voltage source (Keithley 230) to measure the electrical current with an electrometer (Keithley 619). The films were colored in the planar configuration using two silver paint electrodes $5 \mathrm{~mm}$ long at $5 \mathrm{~mm}$ separation. A voltage of $100 \mathrm{~V}$ was applied across the electrodes and the photocurrent response was measured. Data acquisition and analysis were performed using a personal computer.

\section{Results and Discussion}

\subsection{SEM and EDX Measurements}

The analysis of the physical phases was carried out by XRD. Fig. 1 shows the X-ray diffraction patterns of the $\mathrm{SnS}$ thin films exposed to $\mathrm{O}_{2}$ plasma treatment at $20 \mathrm{~min}$ (S2), $40 \mathrm{~min}$ (S3), $60 \mathrm{~min}$ (S4) and $180 \mathrm{~min}$ (S5), including the $\mathrm{SnS}$ thin films in the as-deposited condition (S1). The profiles contain three peaks, at $2 \theta$ $=26.14^{\circ}, 31.55^{\circ}$ and $39.35^{\circ}$, which match the standard pattern for the mineral herzenbergite (PDF \#39-0354), with $\mathrm{SnS}$ composition and orthorhombic structure, corresponding to the crystallographic planes (120), (111) and (131), respectively, as reported previously $[1-7,12,14]$. Also, there is a previous peak that appears at around $22.0^{\circ}$, which is referring to the same pattern with crystallographic plane (110), and a weak evidence of a broad peak at approximately $2 \theta=$ $30.49^{\circ}$ with crystallographic plane (101) is also observed in all the spectrums. It can be observed that there are not very noticeable changes in the diffraction patterns with increasing treatment time.

The crystalline grain sizes of the films were calculated by the Scherrer's formula, and the results are shown in Table 1. From the result we can see that the crystalline grain size increased from $14.67 \mathrm{~nm}$ to $19.9 \mathrm{~nm}$ as the treatment time increased from 20 to $180 \mathrm{~min}$. That means that surface morphology of the sample showed noticeable changes when treatment time increased.

This will be evident from the SEM images discussed in the next paragraph.

The chemical composition of the samples products were analyzed using two methods. The main constituent elements and their relative concentrations were determined by EDX spectroscopy.

Fig. 2 shows the typical chemical composition of the samples products for the sample treated at $60 \mathrm{~min}$

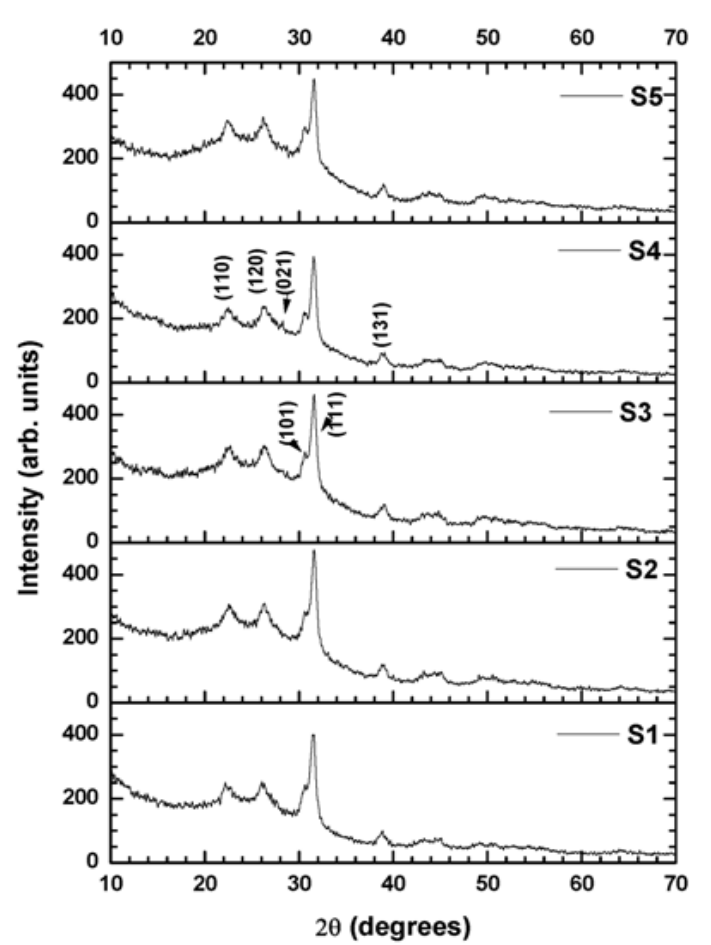

Fig. 1 XRD patterns of SnS thin films with different time of treatment. S1 (0 min), S2 (20 min), S3 (40 min), S4 (60 $\mathrm{min})$ and $S 5$ (180 $\mathrm{min})$.

Table 1 Grain size and Sn-S ratio for tin sulphide thin films treated with oxygen plasma.

\begin{tabular}{lll}
\hline Sample & Grain size $(\mathrm{nm})$ & S:Sn \\
\hline S1 0 (min) & 14.67 & $44.64 / 55.36$ \\
S2 20 (min) & 17.15 & $42.62 / 57.32$ \\
S3 40 (min) & 17.95 & $43.31 / 56.69$ \\
S4 60 (min) & 18.20 & $43.90 / 56.10$ \\
S5 180 (min) & 19.90 & $42.86 / 57.14$ \\
\hline
\end{tabular}




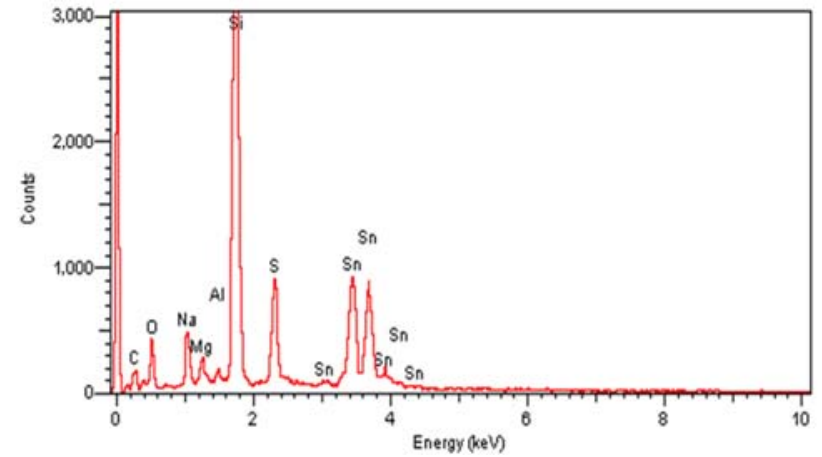

Fig. 2 EDX spectrum of SnS thin films sample treated for $60 \mathrm{~min}$.

Table 2 SnS Particle size for samples treated.

\begin{tabular}{ll}
\hline Sample & Particle size $T_{p}(\mu \mathrm{m})$ \\
\hline S1 $0(\mathrm{~min})$ & 1.12 \\
S2 $20(\mathrm{~min})$ & 1.47 \\
S3 $40(\mathrm{~min})$ & 1.54 \\
S4 $60(\mathrm{~min})$ & 1.56 \\
S5 $180(\mathrm{~min})$ & 1.75 \\
\hline
\end{tabular}

(chemical compositions for as-deposited and treated samples are similar). The structures (peaks) corresponding to $\mathrm{S}$ and $\mathrm{Sn}$ coming from the $\mathrm{SnS}$ thin film can be observed as well as the structures $(\mathrm{Si}, \mathrm{Na}$, $\mathrm{Mg}, \mathrm{Al}$ and $\mathrm{O}$ peaks) corresponding to the glass substrate. The quantitative chemical composition was obtained with a ZAF deconvolution process and the relative concentrations of $\mathrm{Sn}$ and $\mathrm{S}$ on the samples were evaluated.

Table 1 also lists the relative concentrations of $\mathrm{Sn}$ and $\mathrm{S}$ on the samples. It is observed that the $\mathrm{Sn}$ content is increased by about $2 \%$ with the treatment time with the consequent decrease of the content of S. According to the results, the $\mathrm{S}: \mathrm{Sn}$ ratios in the $\mathrm{SnS}$ films are all close to but slightly deviate from the stoichiometric ratio of $\mathrm{SnS}$, which agrees with X-ray observations.

Table 2 listed the particle size $\left(T_{p}\right)$ evolution of the samples. It can be seen that the particle size $\left(T_{p}\right)$ presents an accelerated growth of about $31 \%$ in the first $20 \mathrm{~min}$ (as-deposited sample and sample treated for $20 \mathrm{~min}$, see Figs. 3a and 3b), which mainly consists of larger flocks (clusters) or agglomerates of a certain size accompanied of dispersed particles (whiskers), establishing a markedly increment in the particle size $\left(T_{p}\right)$. Followed of a slow increment of particle size $\left(T_{p}\right)$ between 20 and 60 min (Figs. 3b-3d), it is presumably due to a fragmentation process of the larger flocks after $20 \mathrm{~min}$ and up to $60 \mathrm{~min}$ of treatment.

Finally, it observes an increment in the size particle $\left(T_{p}\right)$ of about $12 \%$ in the last $120 \mathrm{~min}$ (Fig. 3e). This behavior is consistent with the grain size calculated from X-ray observation. The grain sizes measured by $\mathrm{X}$-rays are smaller than those estimated from SEM images. The discrepancy can be attributed to the fact that the grain visualized by SEM is composed of more than one crystallite. Such observations have been found in many cases [26, 27]. The thickness of the films was of $511 \mathrm{~nm}$.

\subsection{Optical Properties}

Figs. 4 and 5 show the optical reflectance $(R)$ and transmittance $(T)$ measurements for the as-deposited and $\mathrm{O}_{2}$ plasma treated $\mathrm{SnS}$ thin films. These figures show that a reflectance of the samples has a very low spectral dependence, except for the as-deposited sample, whose reflectance spectra have a low $(0.1 \%-0.3 \%)$ reflectivity in the visible wavelength range $(400-700 \mathrm{~nm})$ that rises to two maxima around 770 and $980 \mathrm{~nm}$.

The sample treated at $40 \mathrm{~min}$ starts to rise at $780 \mathrm{~nm}$ until $2.4 \%$ at $1,100 \mathrm{~nm}$, showing a slightly maximum

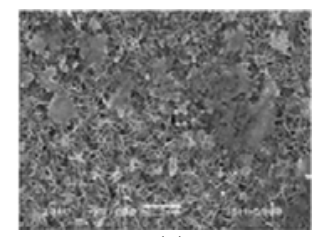

(a)

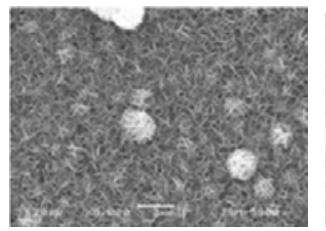

(b)

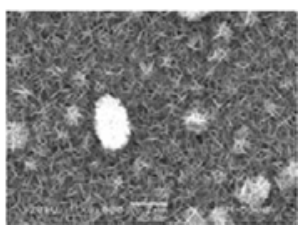

(c)

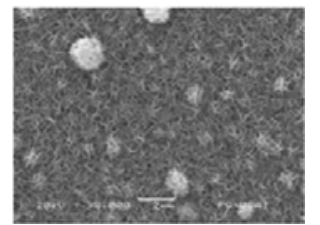

(d)

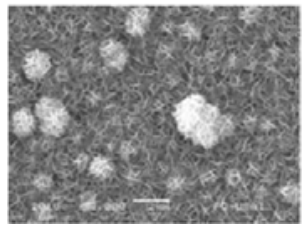

(e)

Fig. 3 SEM images for (a) $0 \mathrm{~min}$, (b) $20 \mathrm{~min}$, (c) $40 \mathrm{~min}$, (d) $60 \mathrm{~min}$ and (e) $180 \mathrm{~min}$ of treatments. 


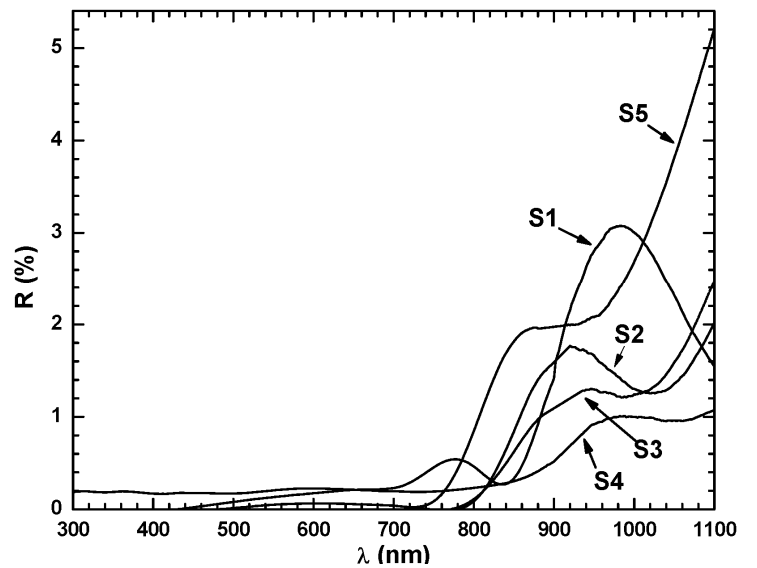

Fig. 4 Specular reflectance spectra for SnS thin film as-deposited and in plasma treatment of $\mathrm{O}_{2}$ at $\mathrm{S} 1(0 \mathrm{~min})$, S2 (20 min), S3 (40 min), S4 (60 min) and S5 (180 min).

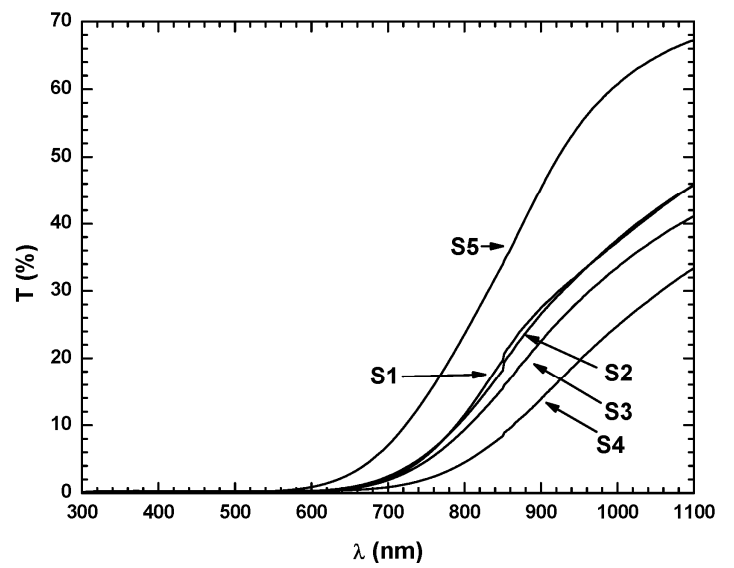

Fig. 5 Optical transmittance spectra for SnS thin film as-deposited and in plasma treatment of $\mathrm{O}_{2}$ at $\mathrm{S} 1(0 \mathrm{~min})$, S2 (20 min), S3 (40 min), S4 (60 min) and S5 (180 min).

at $950 \mathrm{~nm}$. While, the sample treated at $180 \mathrm{~min}$ starts to increase sharply at $740 \mathrm{~min}$ until $5.2 \%$ at 1,100 nm. From the transmittance spectra, a weak shift in the absorption edge is observed towards lower wavelengths as the treated time increases. The as-deposited and treated at 40 min samples start to increase at $620 \mathrm{~nm}$ and rise to $46 \%$ and $41 \%$ at 1,100 $\mathrm{nm}$, respectively. While, the sample treated at $180 \mathrm{~min}$, starts to increase from $560 \mathrm{~nm}$ and rises sharply to $67 \%$ in the near-IR. It found that the samples studied presented high optical absorption coefficient $(\alpha(\lambda))$ value of about $10^{5} \mathrm{~cm}^{-1}$, which were estimated using the data presented in Figs. 4 and 5. The optical band gap of the films was determined from the plot of $(\alpha h v)^{2}$ versus $h v$ and is shown in Fig. 6 and listed in
Table 3. The plot is linear and indicates a direct optical transition.

The as-deposited $\mathrm{SnS}$ thin film has a band gap of $1.61 \mathrm{eV}$, which is in accordance with those reported previously $[1,2,7,8,11,19]$. As the exposition time to the $\mathrm{O}_{2}$ plasma increased, the band gap increased. The increase in direct band gap may be due to the high crystalline order and larger grain size of films as revealed by XRD patterns.

\subsection{Electrical Properties}

The effect of the plasma treatment on the electrical properties of $\mathrm{SnS}$ thin films was evaluated and it is shown in Table 4.

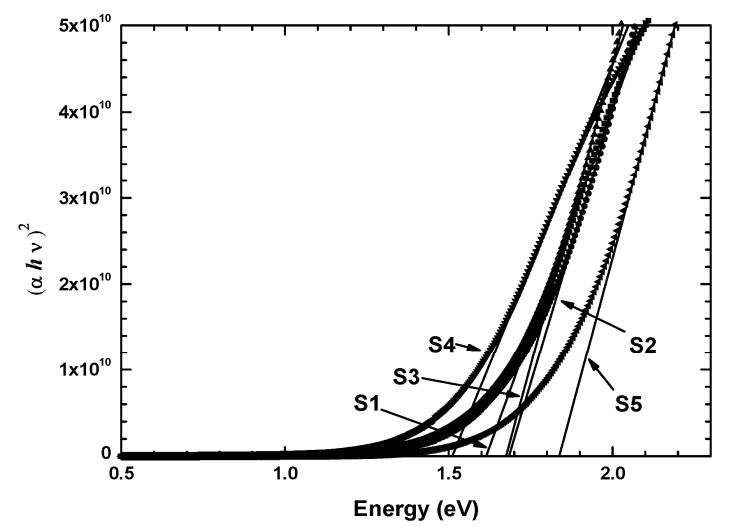

Fig. $6(\alpha h v)^{2}$ vs. $h v$ plots for SnS thin films as-deposited and in plasma treatment of $\mathrm{O}_{2}$ at $\mathrm{S} 1(0 \mathrm{~min}), \mathrm{S} 2(20 \mathrm{~min}), \mathrm{S} 3$ (40 $\mathrm{min})$, S4 (60 min) and S5 (180 min).

Table 3 Values of Band gap determinated for direct transitions.

\begin{tabular}{ll}
\hline Sample & Gap $(\mathrm{eV})$ \\
\hline S1 0 (min) & 1.61 \\
S2 20 (min) & 1.68 \\
S3 40 (min) & 1.67 \\
S4 60 (min) & 1.51 \\
S5 180 (min) & 1.84 \\
\hline
\end{tabular}

Table 4 Electrical conductivity measurements at $\mathrm{S1}(0 \mathrm{~min})$, S2 (20 min), S3 (40 min), S4 (60 min) and S5 (180 min).

\begin{tabular}{ll}
\hline Sample & $\sigma(\Omega \cdot \mathrm{cm})^{-1}$ \\
\hline S1 0 (min) & $2.56 \times 10^{-6}$ \\
S2 20 (min) & $3.50 \times 10^{-5}$ \\
S3 40 (min) & 0.01 \\
S4 60 (min) & 0.13 \\
S5 180 (min) & 0.10 \\
\hline
\end{tabular}


The electrical conductivity value for the as-deposited thin films was $7.0 \times 10^{-6}(\Omega \cdot \mathrm{cm})^{-1}$, similar to that reported previously $[3,8]$. The electrical conductivity is increase by a factor of $10^{4}$ due to $\mathrm{O}_{2}$ plasma treatment. This result is a suitable range of conductivity for the improvement of the solar cell with $\mathrm{SnS}$ as an absorber material.

\section{Conclusions}

The results of the present work can be summarized as follows:

- Good quality SnS thin films were prepared by chemical bath deposition;

- Plasma treatments of these $\mathrm{SnS}$ thin films resulted in modification of their optical and electrical properties. Also their morphology was modified as an effect of $\mathrm{O}_{2}$ plasma treatments;

- There were modifications in the surface morphologies of the thin films depending on the treatment time;

- Optical transmittance spectra and band gap values for the plasma treated $\mathrm{SnS}$ thin films were evaluated. There was considerable decrease in optical transmittance due to the type of the carrier gas used for plasma treatments;

- The band gap value was slightly increased after plasma treatments due to the change in the grain size;

- The conductivity shows a marked increase with the treatment, from $2.56 \times 10^{-6}(\Omega \cdot \mathrm{cm})^{-1}$ for as-deposited film until $0.10(\Omega \cdot \mathrm{cm})^{-1}$ for the film treated at $180 \mathrm{~min}$;

- The results demonstrate the effective use of plasma treatment in modifications of optical and electrical properties of $\mathrm{SnS}$ thin films. Further investigations are in progress to compare the effects of plasma treatments with thermal annealing effects on optoelectronic properties of $\mathrm{SnS}$ thin films.

\section{Acknowledgments}

The authors are thankful to A. González, I. Puente, M.L. Ramón and F. Castillo for technical assistance.
This research was partially sponsored by DGAPA IN-105010, and CONACyT 128714.

\section{References}

[1] F. Jiang, H. Shen, C. Gao, B. Liu, L. lin, Z. Shen, Preparation and properties of $\mathrm{SnS}$ film grown by two-stage process, Appl. Surface Science 257 (2011) 4901-4905.

[2] C. Gao, H. Shen, Influence of the deposition parameters on the properties of orthorhombic $\mathrm{SnS}$ films by chemical bath deposition, Thin Solid Films 520 (2012) 3523-3527.

[3] Y. Jayasree, U. Chalapathi, P.U. Bhaskar, V.S. Raja, Effect of precursor concentration and bath temperature on the growth of chemical bath deposited tin sulphide thin films, Appl. Surface Science 258 (2012) 2732-2740.

[4] H. Martinez, D. Avellaneda, Modifications in SnS thin films by plasma treatments, Nuclear Instruments and Methods in Physic Research 272 (2012) 351-356.

[5] C. Gao, H. Shen, L. Sun, Z. Shen, Chemical bath deposition of SnS films with different crystal structures, Materials Letters 65 (2011) 1413-1415.

[6] F. Jiang, H. Shen, W. Wang, L. Zhang, Preparation of $\mathrm{SnS}$ film by sulfurization and $\mathrm{SnS} / \mathrm{a}-\mathrm{Si}$ heterojunction solar cells, J. Electrochem. Soc. 159 (2012) H235-H238.

[7] J. Malaquias, P.A. Fernandes, P.M.P. Salomé, A.F. da Cunha, Assessment of the potential of tin sulphide thin films prepared by sulphurization of metallic precursors as cell absorbers, Thin Solid Films 519 (2011) 7416-7420.

[8] M.R. Fadavieslam, N. Shahtahmasebi, M. Rezaee-Roknabadi, M.M. Bagheri-Mohagheghi, A study of the photoconductivity and thermoelectric properties of $\mathrm{Sn}_{\mathrm{x}} \mathrm{S}_{\mathrm{y}}$ optical semiconductor thin films deposited by the spray pyrolysis technique, Phys. Scr. 84 (2011) 035705.

[9] M. Calixto-Rodriguez, H. Martinez, A. Sanchez-Juarez, J. Campos-Alvarez, A. Tiburcio-Silver, M.E. Calixto, Structural, optical, and electrical properties of tin sulfide thin films grown by spray pyrolysis, Thin Solid Films 517 (2009) 2497-2499.

[10] T.H. Sajeesh, A.R. Warrier, C.S. Kartha, K.P. Vijayakumar, Optimization of parameters of chemical spray pyrolysis technique to get $n$ - and p-type layers of SnS, Thin Solid Films 518 (2010) 4370-4374.

[11] N.R. Mathews, H.B.M. Anaya, M.A. Cortes-Jacome, C. Angeles-Chavez, J.A. Toledo-Antonio, Tin sulfide thin films by pulse electrodeposition: Structural, morphological, and optical properties, J. Electrochem. Soc. 157 (2010) H337-H341.

[12] K. Hartman, J.L. Johnson, M.I. Bertoni, D. Recht, M.J. Aziz, M.A. Scarpulla, et al., SnS thin-films by RF sputtering at room temperature, Thin Solid Films 519 (2011) 7421-7424. 
[13] O.E. Ogah, G. Zoppi, I. Forbes, R.W. Miles, Thin films of tin sulphide for use in thin film solar cell devices, Thin Solid Films 517 (2009) 2485-2488.

[14] O.E. Ogah, K.R. Reddy, G. Zoppi, I. Forbes, R.W. Miles, Annealing studies and electrical properties of SnS-based solar cells, Thin Solid Films 519 (2011) 7425-7428.

[15] P. Sinsermsuksakul, J. Heo, W. Noh, A.S. Hock, R.G. Gordon, Atomic layer deposition of tin monosulfide thin films, Advance Energy Materials 1 (2011) 1116-1125.

[16] M. Salavati-Niasani, D. Ghanbri, F. Davar, Shape selective hydrothermal synthesis of tin sulfide nanoflowers based on nanosheets in the presence of thioglycolic acid, J. Alloys Compd. 492 (2010) 570-575.

[17] Y. Rodríguez-Lazcano, H. Martínez, M. Calixto-Rodríguez, A. Núñez Rodríguez, Properties of $\mathrm{CuS}$ thin films treated in air plasma, Thin Solid Films 517 (2009) 5951-5955.

[18] G. González, B. Krishnan, D. Avellaneda, G. Alan Castillo, T.K. Das Roy, S. Shaji, Modification of optical and electrical properties of chemical bath deposited CdS using plasma treatments, Thin Solid Films 519 (2011) 7587-7591.

[19] M. Calixto-Rodriguez, H. Martinez, Y. Peña, O. Flores, M.E. Esparza-Ponce, A. Sánchez-Juarez, et al., A comparative study of the physical properties of $\mathrm{Sb}_{2} \mathrm{~S}_{3}$ thin films treated with $\mathrm{N}_{2}$ AC plasma and thermal annealing in $\mathrm{N}_{2}$, Appl. Surface Sci. 256 (2010) 2428-2433.

[20] M. Calixto-Rodriguez, H. Martinez, A. Sanchez-Juarez,
AC plasma induced modifications in $\beta-\operatorname{In}_{2} S_{3}$ thin films prepared by spray pyrolysis, Thin Solid Films 517 (2009) 2332-2334.

[21] D. Avellaneda, M.T.S. Nair, P.K. Nair, Polymorphic tin sulfide thin films of zinc blende and orthorhombic structures by chemical deposition, J. Electrochem. Soc. 155 (2008) D517.

[22] D. Avellaneda, G. Delgado, M.T.S. Nair, P.K. Nair, Structural and chemical transformations in $\mathrm{SnS}$ thin films used in chemically deposited photovoltaic cells, Thin Solid Films 515 (2007) 5771.

[23] M.M. Bagheri-Mohagheghi, N. Shahthmasebi, M.R. Alinejad, A. Youssefi, M. Shokooh-Saremi, Fe-doped $\mathrm{SnO}_{2}$ transparent semi-conducting thin films deposited by spray pyrolysis technique: Thermoelectric and p-type conductivity properties, Solid State Sci. 11 (2009) 233-239.

[24] R.N. Koteesqara, R.K.T. Ramakrishna, SnS films for photovoltaic applications: Physical investigations on sprayed $\mathrm{Sn}_{\mathrm{x}} \mathrm{S}_{\mathrm{y}}$ films, Physica B 368 (2005) 25-31.

[25] M. Regragui, M. Addou, A. Outzourhit, J.C. Bernéde, E.E. Idrissi, Preparation and characterization of pyrolytic spray deposited electrochromic tungsten trioxide films, Thin Solid Films 358 (2000) 40-45.

[26] L. Dghoughi, B. Elidrissi, C. Bernède, M. Addou, M.A. Lamrani, M. Regragui, Physico-chemical, optical and electrochemical properties of iron oxide thin films prepared by spray pyrolysis, Appl. Surf. Sci. 253 (2006) 1823-1829. 